\title{
A Multimodal Discourse Analysis of the Notion of Beauty in "Dove Real Beauty Sketches"
}

\author{
Janice Davita Oey \\ English Department, Faculty of Letters, Petra Christian University, Siwalankerto 121-131, Surabaya \\ 60236, INDONESIA \\ E-mail: janicedavita@gmail.com
}

\begin{abstract}
This research deals with multimodality or multimodal discourse analysis in analyzing the notion of beauty in a Youtube video. It aims at finding how an advertisement uses the multiple modes in constructing the meaning, which is the notion of beauty. For this research, the object of the analysis is Dove's video advertisement entitled "Dove Real Beauty Sketches", which was uploaded to the YouTube channel of Dove in 2013. The issue that Dove is trying to convey through the advertisement is that beauty is in the eye of the beholder. One's perception of beauty can differ from another. If one person describe himself/herself as unattractive, other people may think that the person is actually attractive. Through this research, I want to find how that issue is constructed through the analysis of the multiple modes used in the advertisement. The multiple modes consist of the verbal and non-verbal expressions displayed by the female participants, Olivia, Melinda, Kela, and Florence.
\end{abstract}

Keywords: advertisement, beauty, notion, multimodal discourse analysis

\section{INTRODUCTION}

The existence of advertisement is very common in this modern era. It helps with promoting a product that a company is selling or just simply promoting a cause such as charity, donations, and social awareness. In order to buy a product, people need be convinced. The most effective method to persuade people is through advertisements. A great advertisement must have a strong message in order to be able persuade and convince the viewers to purchase their product. Advertisements can be in the form of text that we can see in newspapers, in the form of audio where we can listen to them, or in the form of video where we can watch them. Video form of advertisement is the most common, especially with the existence of social media. Social media, as we know, is the most popular platform of media because the accessibility of it. Because most people in the world have access to social media, most companies nowadays make video advertisements and put them in social media. It is the most effective way so that their advertisements can be seen by people and persuade people to buy the products that they sell.

One of the social media that is popular today is YouTube. There are millions of videos that are in YouTube. Some part of those videos are advertisement videos. Video advertisements on YouTube are product or service advertisements. Most of the advertisements are brands that have the purpose of selling their products. However, there are also many advertisements that are not always about marketing a product, but there are implicit "ideas" or "messages" that the advertisement and the brand maker hope can be communicated to the viewers. Up to this day, there are many brands advertisements that have the same concept. They are not just selling products, but also an "idea" that a company wishes to be convey. In some advertisements, the messaged are very important social messages that aims to give positive influence to the viewers. One of the social messages that we can see in the advertisements these days is about self-love. Many beauty companies are shouting out messages about self-love. 
Many women and men have difficulties in self-love, especially about their beauty. People have problem in self-love in terms of beauty because the intangible rule where people of the world have to follow the fixed standard of beauty. This standard of beauty is delivered to the norms of the people because it is reflected on the media. Media has a very powerful and impactful influence on the people's point of view. People see the media as the provider of reality, that makes them become influenced by the "reality" that the media provide. The women depicted in $\mathrm{TV}$, magazines, films and advertisements are supposed to have flawless skin, perfect hair, tall and slender body and ideal body proportions (Vitelli, 2013). The depiction of a handsome man is by having perfect skin, tall and muscular body, and actor-like face. That common view of beauty in men and women does not reflect in reality. There are women and men who are stubby, have acnes on their face, and have imperfections like scars. The effect of seeing the beauty depicted in media is that people feel that they are less than the people that are represented in TV that they watch or magazines that they read. People should embrace their uniqueness. People do not have to follow the common idea of beauty that is depicted by the media to be able to be beautiful. Their own body is already enough to be called beautiful and both women and men should always appreciate their unique beauty. One company that implement this social message in their advertisement is Dove. They implement the social message through the "Dove Real Beauty Sketches". In the advertisement that they post on YouTube, they try to communicate the view of how people can have different notions of beauty to their viewers. The different notion is that one person can say that having freckles is a flaw, but another person may also say that the freckles are someone's beauty mark. The message is very important for people to know, amidst the many radical view of having to be perfect.

From the issue that exists in the advertisement, the problem of my research is to see how people can have different notions of beauty. To solve the problem, I used theory from Brian Paltridge (2012) of Multimodal Discourse Analysis. In Paltridge's book, he mentioned that media like an advertisement, consists of multiple modes. The multiple modes or semiotic resources which are the combination of gestures, images, music, and voice that create meaning (Paltridge, 2012). Those modes exist in Dove beauty advertisement and the combination of the modes create a meaning which is the different notions of beauty. In addition, I will also find out how the combination of the different semiotic resources in the advertisement helped Dove to construct the meaning of the advertisement and deliver it to the viewers.

I analyzed the topic using the Multimodal Discourse Analysis approach. There are many theories that exist in the branch of Multimodal Discourse. However, the theory that I will use in this research is Brian Paltridge's approach in Multimodal Discourse. The approach is on how the combination of different modes (multimodality) in a single form of media such as advertisement or newspaper text is able to not only create meaning, but also to convey that meaning towards the readers or audience. Since the main focus in this research is Paltridge's theory of Multimodal Discourse Analysis, I will use the modes that can be found in the video. Those modes are the gestures, facial expressions, eye contact, sound, and verbal expressions that are produced by the participants in the video. According to Paltridge (2012), Multimodal Discourse Analysis deals with how texts draw on modes of communication such as pictures, film, video, images, and sound in combination with words to make meaning (2012, p. 170). Multimodal Discourse Analysis is how the meaning of a text constructed from the combination of different modes contained in it. The media that we see and access on our daily activities these days are not depending on either audio or visual only. The focus of Multimodal Discourse Analysis is that readings are constructed not just by the use of words but by the combination of words with other modalities, such as pictures, film, video images, and sound (Paltridge, 2012). The situation can be seen from the Dove video advertisement that I used for my analysis. In this research, this theory is applied in my data analysis to answer my research questions and discover how the combination of different semiotic resources can create a meaning or message of the video, which is the different notion of beauty. The multiple modes (facial expressions, 
gestures, voice) that can be found from the advertisement video will help me in analyzing how the four woman participants show their negative notion about themselves and also how the positive notion from other people construct the "meaning" of notions of beauty in the Dove advertisement. The notion of beauty is the main focus of my research and enabled me to answer the research questions. This theory will be used so that the viewers can understand better how multimodality is reflected in Dove's Real Beauty Sketches beauty campaign to create the meaning that the video conveyed.

\section{METHOD}

I will analyze the modes of communication displayed by the four participants: Olivia, Melinda, Kela, and Florence, using Paltridge's Multimodal Discourse Analysis. There are four multiple modes that will be analyzed in this research. Those modes are facial expressions, sound, verbal expressions, and gaze. The video will be analyzed using qualitative approach to help me in solving the problem of how multiple modes can construct different notions of beauty (Kitto, S. C., Chesters, J., \& Grbich, C., 2008). The video advertisement from Dove is a six-minute video that consist of the four female participants: Melinda, Olivia, Kela, and Florence who were asked to describe themselves to a facial sketcher from the police force named Gil Zamora. Besides the four women, there are also other participants who were asked to describe the four women participants' facial features. In the video, the sketcher, Gil, asked the participants, Olivia, Melinda, Florence, and Kela, to describe their own facial features, which are their chin, eyebrows, and hair to the sketcher. When the sketcher finished the sketches of the four women, the other group of people are interviewed one by one to describe about particular facial features of the four women participants. While Gil was listening to the description of the four women participants, he was sketching them on paper. Gil and the four women were separated by a curtain that made him unable to see what the women faces looked like. He sketched by only relying on his listening of the four women and the other people's description. The sketches were revealed to the four women after the sketcher finished all of his sketching sessions with the four women and the other group of people. Dove's goal is to get another perspective of the participants' description other than their own.

My analysis will compare the participants' own description and the other people's description about the participants: Olivia, Melinda, Kela, and Florence. Before the sketching session started, the two of the four women participants were asked several questions by Dove's team about their opinions about their appearance. The data is the multiple modes that were taken from Dove's beauty campaign video titled "Dove Real Beauty Sketches-You're more beautiful than you think". The video can be accessed from Dove US's YouTube channel (https://www.youtube.com/watch? $\mathrm{v}=\mathrm{litXW}$ 91UauE\&t=7s). The video's duration is six minutes and thirty five seconds. The participants of Dove's "You are more beautiful than you think" are women who are in their 30s or over. Most of the women are of Caucasian race. The type of data that I took is the multiple modes that is shown in the video (gestures, dialogs, images). The resources that I collect as my data are both verbal and visual because I want to know the meaning that is produced by the combination of resources that are produced by the participants.

The first step of data collection that I do is watching the beauty campaign video. After watching it two times, I made the raw transcription of the video by typing down only the dialogs that are spoken in the video. I also wrote down the names of the participant that were mentioned in the video. After making the raw translation, I watched the video again and pause every now and then to record the actions and expressions that the participants made. My method of recording the actions and expressions is by taking screenshots of them. The screenshots enable me to capture the expression a person made when /after they said a certain dialog. I do this in order to complete my transcription so that I can do my analysis more easily. I analyze the data by 
catching the modes that I get from the dialog and the screenshot that I have taken. From the modes that I get, I was able to get what meaning the advertisement is trying to construct.

\section{ANALYSIS AND FINDINGS}

The analysis and findings of my research is to solve the problem of my research, how Dove used multiple modes to create the meaning: the different notions of beauty. Dove constructed the message by using different modes such as gestures and facial expression that can be found in the beauty campaign video. The findings that are provided is the result of analyzing the multiple modes found in the object of my study. The multiple modes discussed in this chapter is not just the verbal expressions, but also the visual expressions, such as their eyes, facial expression, and more.Through my analysis of the object, I found that the multiple modes used in the advertisement are facial expressions, sound, verbal expressions, and gaze. The gaze seen in the video are made by the participants when they want to express their lack of confidence. In Olivia's interview she can be seen looking down after uttering that she would change her lips shape and want it to be fuller.

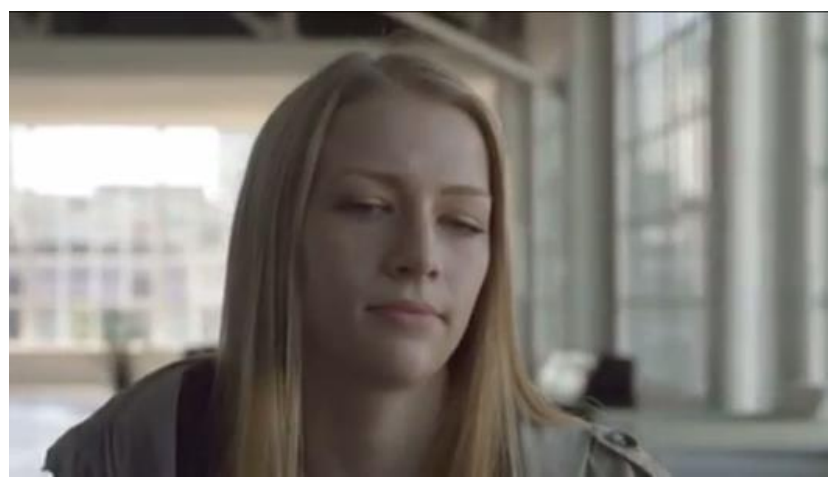

(Figure 1)

After stating that, she looks down to show her feeling of shame and regret. She showed the expression in figure 1, because even if she said that she wants fuller lips, she will never have them. Her looking down shows that her gaze and posture, as semiotic resources, both contribute to the means where she is not confident with her current appearance (Paltridge, 2012, p.171). The modes of gaze or eye contact can be seen from Kela's interview where she rolls her eyes and avoids eye contact (figure 2) with the interviewer and the camera. According to Paltridge, avoidance of eye contact towards the camera indicated the lack of her confidence (2012, p.172).

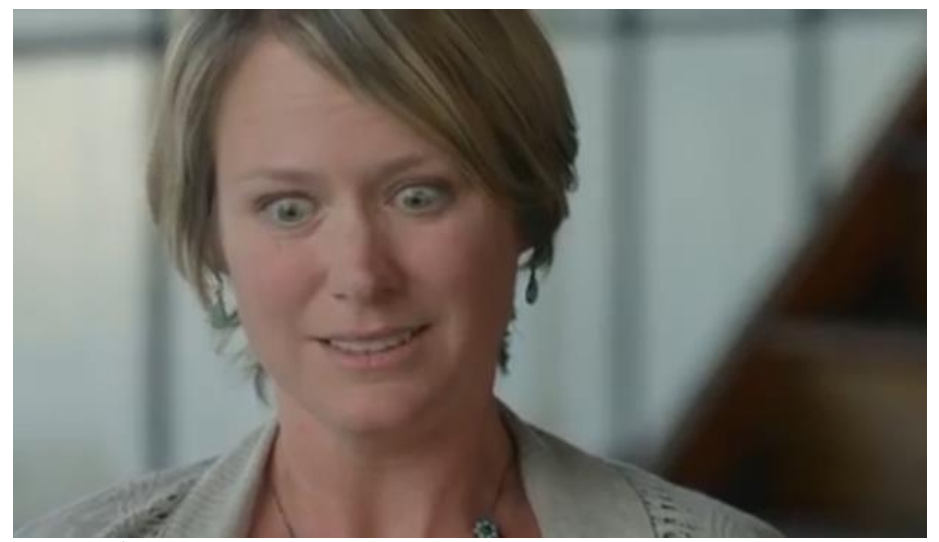

(Figure 2) 
The mode of sound can be seen from when Melinda was describing herself. She told a personal experience where people always remind her that her face is always looking tired. When people reminded her, she would say "Oh,man" because she is being reminded of something negative about her face. Sound and verbal expression are the semiotic resources that can indicate the feeling of the speaker (2012, p.170). In this research, the intonation in Melinda's verbal expression "Oh, man" indicates her lack of confidence. Following that, when Melinda were asked on how she would describe her hair. She answered by uttering:"Hum.. brown, long. [thinking face] I guess a little bit passed my shoulders". From her utterance it can be seen that she makes a pause by saying "hum.." when describing her hair. The "hum.." followed by a thinking face showed that she is not confident enough of her hair to describe it to Gil (2012, p.171).

From my findings, I can conclude that the four women participants of the video has some kind of similarity or pattern. Dove assembled women participants who have very low-esteem of themselves for this advertisement. The women were people who are not satisfied with their current physical appearances. When they were asked to describe themselves, they would show hesitation and not confident about describing their facial features. However, the other participants who were asked to describe the four women, they give positive remarks about the women. Also, after seeing how the descriptions that the women gave and other people gave, the women changed their opinions and started to see themselves positively. The different opinions or perspectives solves the problem on how Dove reflected the different notions of beauty through the multiple modes. Dove uses the different modes to convey that when people talk about their negative side, they make expressions that "lower" themselves. Their voices would go slower and the tone would go lower as well. It shows what they are not confident with. The verbal expressions that they uttered showed that they wish they would have the opportunity to have better facial features that what they have at the moment. A different situation occurs when they were talking about others, they would talk about the others' strengths with joy. The facial expressions brighten and the tone of their voice also become higher and I can feel that they are happy when talking about someone else. Dove wanted to show that most people are not always happy with themselves, even though it is their own body and personality.

\section{CONCLUSION}

In findings and analysis chapter it can be found that the video contained multiple modes which are the facial expressions, sound, eye contact, and verbal expressions. In my analysis, the expressions are used to draw out meanings from each of the women's utterance. Those expressions are portrayed as gestures, facial expression, and voice tone in the video (Paltridge, 2012, p.170). In addition, the expressions are the multiple modes that Dove use in this beauty campaign in order to produce the meaning of "The notion of beauty". In order to find how the connection between the multiple modes create meaning of the video, I used the theory of multimodal discourse analysis by Brian Paltridge (2012). The use of the theory is to draw means of communication that is done through the use of images and verbal expressions that are produced by the participants of the video. The different notion of beauty can be seen from the description of the women, Florence, Olivia, Kela, and Melinda, during their session of sketching with the police sketcher, Gil Zamora. Beauty is not something fixed and uniformed for every person. A woman can view herself as not beautiful, but other people may not think that way. One woman's negative perception of herself will certainly project herself as ugly and unattractive to other people.

My suggestion for the research is that to give the researcher more time to do the research in order to have deeper understanding towards the research and the topic of research. If the researcher have deeper understanding of the topic and object of research, it will have effect in 
deeper explanation of both the topic and object in the research. The readers will also have deeper understanding of the research because of the more in-depth explanation.

\section{REFERENCES}

Kitto, S. C., Chesters, J., \& Grbich, C. (2008). Quality in Qualitative Research. The Medical Journal of Australia, 243-246.

Kress, G., \& van Leuwen, T. (2006). Reading Images: The Grammar of Visual Design. London: Routledge.

Machin, D. (2007). Introduction to Multimodal Analysis. Bloomsbury.

Mahendra, L. T. (2015). Meaning in American Dove shampoo commercial campaign.

Meriam-Webster. (n.d.). Retrieved September 2018, from Meriam-Webster DIctionary: http://www.merriam-webster.com

Oxford. (2013). Oxford Advanced Learner's Dictionary. Oxford University Press.

Paltridge, B. (2012). Discourse Analysis. London: Bloomsbury Academic.

Semiotix. (n.d.). Language as social semiotic in Halliday's systemic functional linguistics. Semiotix A Global Information Magazine. Retrieved November 27, 2018, from https://semioticon.com/semiotix/2012/03/language-as-social-semiotic-in-hallidayssystemic-functional-linguistics/

Vitelli, R. (2013, November 18). Media Exposure and the "Perfect" Body. Psychology Today. 